\title{
Fatal ball-valve airway obstruction by an extensive blood clot during mechanical ventilation
}

\author{
P. Foucher, M. Merati, N. Baudouin, O. Reybet-Degat, Ph. Camus, L. Jeannin
}

Fatal ball-valve airway obstruction by an extensive blood clot during mechanical ventilation. P. Foucher, M. Merati, N. Baudouin, O. Reybet-Degat, Ph. Camus, L. Jeannin. (C) ERS Journals Ltd 1996.

ABSTRACT: A ball-valve airway obstruction by a blood clot cast of almost the whole bronchial tree occurred in a small-cell lung cancer patient, who had been on mechanical ventilation for 9 days.

Chest radiographs revealed overinflated lungs. Attempts to remove the cast via fibreoptic bronchoscopy were unsuccessful and the patient died. A postmortem extraction of the clot was performed with a rigid tube.

This case is rare because of absence of severe haemoptysis and lung volume reduction.

Eur Respir J., 1996, 9, 2181-2182.
Dept of Pulmonary Diseases, University Hospital, Dijon, France.

Correspondence: P. Foucher Dept of Pulmonary Diseases University Hospital "le Bocage" 21034 Dijon Cedex France

Keywords: Airways obstruction, blood clot bronchoscopy, mechanical ventilation

Received: May 311996

Accepted after revision July 21996
Fatal obstruction of the lower airways by large casts is uncommon [1, 2]. Besides foreign bodies [3], bronchial casts usually consist of either abnormal bronchial mucous (hypersecretion or hyperviscosity) $[2,4,5]$ or blood clots $[1,3,5-10]$. We report a fatal case of ball-valve obstruction of the airways by an extensive blood clot, with no clinically apparent severe haemoptysis.

\section{Case report}

A 65 year old male was referred for evaluation of mediastinal masses discovered on chest radiographs. His medical history revealed a right hemiplegia a few years previously, with no subsequent symptoms. He was formerly a heavy tobacco smoker. For 2 months, he had complained of weight loss (13 kg), weakness and increasing dyspnoea, together with a mild cough and sputum. On arrival, a dysphonic voice was clearly noticeable. His performance status was poor, but physical examination yielded fairly normal results. Chest radiography confirmed the enlargement of the mediastinum, with no evidence of parenchymal involvement. The results of routine laboratory investigations, including coagulation tests, were within normal ranges.

Soon after arrival, a fibreoptic bronchoscopy was performed. The left vocal cord was paralysed, the trachea was normal but the carina was widened, suggesting the presence of subcarinal lymph nodes. Diffuse bronchial mucosal erythema and oedema, as well as external compression were observed in the two mainstem bronchi, resulting in a $50 \%$ loss in diameter. No exophytic lesion was present. Several biopsies were performed and a small-cell lung cancer was discovered. A computed tomography (CT) scan confirmed the presence of mediastinal lymph nodes without parenchymal involvement. No metastatic disease was found.

Combination chemotherapy was started (cyclophosphamide, etoposide and doxorubicin). A few hours later
(Day 1), the patient presented a sudden onset of dyspnoea. He was, therefore, transferred to the intensive care unit (ICU). His dyspnoea improved with i.v. steroids, oxygen and suctioning with a fibreoptic bronchoscope (neither blood nor macroscopic modifications were found). No changes were observed in chest radiographs. On Day 2 , the same scene recurred but medical management was ineffective. A fibreoptic bronchoscopy revealed a worsening obstruction of the mainstem bronchi, with severe infiltration of the mucosa, thick mucus and traces of blood. The patient was then placed on volume-controlled mechanical ventilation through an endotracheal tube (ET). A dramatic improvement was achieved.

From Day 2 to Day 8, the patient was ventilated easily (normal insufflation pressure) with normalization of blood gases, but suctioning was described by nurses as increasingly difficult and mildly blood-tinged. No atelectasis was seen on radiographs but overinflation of the right lung should have been suspected on Day 8 (fig. 1) as compared to the Day 1 chest radiograph, whilst right lung sounds were decreasing.

On day 9 , insufflation pressure rose progressively from normal up to $50 \mathrm{cmH}_{2} \mathrm{O}$ and a bronchoscopy was planned, but the patient went into sudden respiratory distress. The fibreoptic bronchoscopy revealed that the two main stem bronchi were almost completely obstructed by solid casts, coming up to the last centimetres of the trachea, without any obstruction or contact with the ET tube. Both suctioning and the use of small forceps proved ineffective. A rigid tube bronchoscopy was prepared but the patient went into unrecoverable cardiac arrest and died. This examination was, however, continued in order to understand the nature of the cast. By using large forceps through the bronchoscope it was possible to extract a surprising cast of the bronchial tree almost entirely intact, except for the upper right-hand lobe (fig. 2). When the cast was extracted, the lungs suddenly deflated with a hissing sound. Histological examination confirmed a 


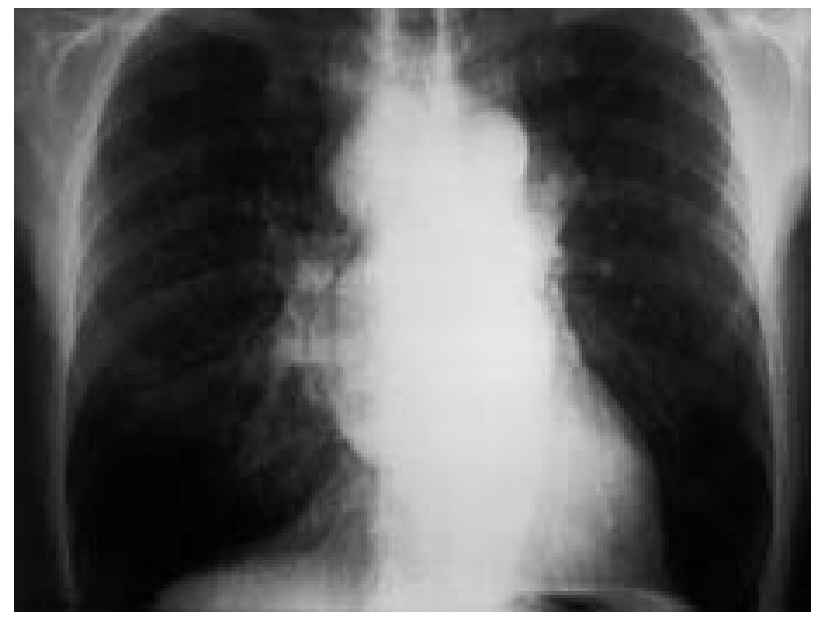

Fig. 1. - Chest radiograph on Day 8, showing large mediastinal masses corresponding to the small-cell lung cancer. The filling defect in the tracheal air column and the right lung overinflation are clearly visible.

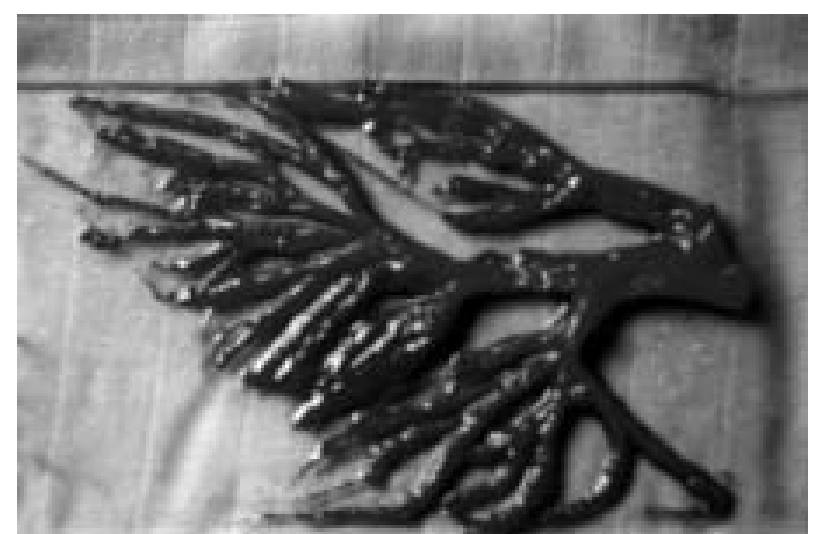

Fig. 2. - Tracheobronchial blood clot cast removed by means of rigid bronchoscope. The first branching on the right is the carina. Only the right upper lobe is missing (top of the picture).

homogeneous blood clot, with no evidence of tumour cells. Examination of the bronchial tree after removal of this clot showed similar findings compared with those of the first bronchoscopy. Alterations of the coagulation profile due to chemotherapy were mild at the time of death (platelet value $=90 \times 10^{9} \cdot \mathrm{L}^{-1}$, prothrombin time $=93 \%$, activated partial thromboplastin time $=1.4$ times control).

\section{Discussion}

Many clinical situations could lead to formation of airway mucous casts, including bacterial pneumonia, asthma, cystic fibrosis or allergic bronchopulmonary aspergillosis, but blood clot casts are usually preceded by severe or massive haemoptysis $[1,5-8,10]$. Massive haemoptysis is usually defined as more than $600 \mathrm{~mL}$ blood in a $24 \mathrm{~h}$ period. In this case, no severe haemoptysis was noticed, but only mild blood-tinged suction products that are not unusual in ventilated patients. $\mathrm{Mu}-$ cosal damage observed during endoscopy is likely to have been responsible for a minimal but diffuse and continuous bleeding, worsened by progressive outbreak of post chemotherapy coagulation disorders on the last two days.
In spite of its extent, this cast did not cause a radiological lung collapse but overinflation, particularly noticeable in the right lung (fig. 1). This so-called ball-valve mechanism has already been described [7,8] and can quickly be life-threatening, especially in a patient on mechanical ventilation, due to the increase in intrinsic positive end-expiratory pressure leading eventually to the development of a tension pneumothorax [7]. The filling defect in the tracheal air column was visible on radiography (fig. 1), but was attributed to neoplasic lesions. The great speed of formation of the clot is usually stressed in the literature, as demonstrated by the relative normality of endoscopy some hours or days beforehand [5, 7]. However, unfortunately, no fibreoptic examination was performed between Day 2 and 9 for this patient because of the lack of atelectasis on radiographs. The very unusual extent of this clot and the surprising complete lack of adhesion were probably favoured by positive pressure ventilation.

The failure to dislodge the clot using the fibreoptic bronchoscopy is, in this case, easily understood. The removal of such a cast through an endotracheal tube is, moreover, risky since acute blocking up of the tube may occur. For the same reason, streptokinase [9] or Fogarty balloon-tip embolectomy [6] would probably not have been successful. The extreme ease of removal of the entire cast by means of rigid bronchoscopy suggests that this method of mechanical removal should have been tried first.

We believe that blood-tinged suction products should not be considered of little significance in patients on mechanical ventilation, and that repeated fibreoptic bronchoscopy is required, even in cases where chest radiographs reveal no evidence of lung collapse.

\section{References}

1. Greenberg JE, Fischl MA, Berger JR. Upper airway obstruction secondary to acquired immunodeficiency syndrome-related Kaposi's sarcoma. Chest 1985; 88: 638-640.

2. Burton GG, Wagshul FA, Henderson D, Kime SW. Fatal airway obstruction caused by a mucous ball from a transtracheal oxygen catheter. Chest 1991; 99: 1520-1523.

3. Sprung J, Bourke DL, Harrison C, Barnas GM. Endotracheal tube and tracheobronchial obstruction as causes of hypoventilation with high inspiratory pressures. Chest 1994; 105: 550-552.

4. Ravikrishnan KP, Dircks JW. Tracheobronchial cast. Chest 1977; 71: 241-242.

5. Fairshter DR, Riley CA, Hewlett RI. Large bronchial casts. Arch Intern Med 1979; 139: 522-525.

6. Allen RP, Siefkin AD. Emergency airway clot removal in acute hemorrhagic respiratory failure. Crit Care Med 1987; 15: 985-986.

7. Popovich J Jr, Babcock R. Intraluminal blood clot casts causing obstructive emphysema and recurrent pneumothorax. Crit Care Med 1982; 10: 482-483.

8. Kruczek ME, Hoff BH, Keszler BR, Smith RB. Blood clot resulting in ball-valve obstruction in the airway. Crit Care Med 1982; 10: 122-123.

9. Cole PR, Grossman GJ. Endobronchial streptokinase for bronchial obstruction by blood clots. N Engl J Med 1983; 308: 905-906.

10. Skatrud J, Gilbert R, Auchincloss JH Jr, Rana S. Blood clot cast following hemoptysis and resulting in atelectasis. Chest 1976; 69: 131. 